IFN Working Paper No. 813, 2009

\title{
Taxation and the Quality of Entrepreneurship
}

Andrea Asoni and Tino Sanandaji 


\title{
Taxation and the Quality of Entrepreneurship*
}

\author{
Andrea Asoni ${ }^{\dagger}$ and Tino Sanandaji ${ }^{\ddagger}$ \\ Research Institute of Industrial Economics
}

October 28, 2013

\begin{abstract}
We study the effect of taxation on entrepreneurship, investigating how taxes affect both the number of start-ups and their average quality. We show theoretically that even with risk neutral agents and no tax evasion progressive taxes can increase entrepreneurial entry, while reducing average firm quality. So called "success taxes" encourage start-up with lower value business ideas by reducing the option value of pursuing better projects. This suggests that the most common measure used in the literature, the likelihood of entry into self-employment, may underestimate the adverse effect of taxation.
\end{abstract}

Key Words: Taxation, Entrepreneurial Entry, Quality of Entrepreneurial Firms JEL Classification: H24, H25, L26

\footnotetext{
${ }^{*}$ We thank Henrik Horn, Lars Persson, Raaj Sah, the participants in the IFN Brown Bag seminar and two anonymous referees for valuable comments. All remaining errors are our own.

${ }^{\dagger}$ Charles River Associates, Washington DC and IFN - Research Institute for Industrial Economics. Stockholm, Sweden. The views presented here are my own and do not necessarily reflect those of CRA or any CRA employee.

${ }^{\ddagger}$ IFN - Research Institute for Industrial Economics. Stockholm, Sweden.
} 


\section{Introduction}

Entrepreneurship is generally viewed as an important determinant of innovation and growth. For this reason public policy has focused on entrepreneurial activity and on the organizational form in which it often takes place: self-employment. One of the main components of entrepreneurial public policy in all developed countries is the taxation of the self-employed. However, empirical estimates of the effect of taxation on the level of entrepreneurship is generally inconclusive (Bruce and Schuetze 2004). One reason is that entrepreneurship is a somewhat vague concept, hard to define exactly and harder still to measure. Kanniainen and Panteghini (2013) argue that the analysis of taxes must take into account the fact that entrepreneurship is complex and involves several simultaneous decision margins. The authors show that even in situations where taxes are neutral with respect to the entrepreneurial investments, taxes may distort the occupational choice: whether to become an entrepreneur in the first place. Another reason for the lack of consensus regarding the effect of taxes is that the theoretical prediction regarding the relationship between taxation on entrepreneurship is ambiguous.

There are at least four ways in which taxation can affect entrepreneurial entry (Bruce and Gurley 2004). Most simply, the effect of taxes is to lower returns on effort and risk taking; personal taxes on entrepreneurs reduce investments, hiring and firm growth (Carroll et al. 2000a, 2000b, 2001). On the other hand, taxes can stimulate risk taking activities by compressing the distribution of after-tax returns, at least for the marginal investment, when losses are fully deductible (Domar and Musgrave 1944). Taxes can also increase selfemployment if entrepreneurs face lower taxes than employees or if self-employment makes it 
easier to evade taxes (Gordon and MacKie-Mason 1994; Gordon 1998; Bruce 2000; Cullen and Gordon 2007, Stenkula 2012).

When taxes are progressive rather than flat, a fourth mechanism has been suggested. Since entrepreneurial returns are more dispersed than wages, the progressivity of the tax schedule matters as well as the level of taxation. In an influential paper Gentry and Hubbard (2000) demonstrate that high marginal tax rates discourage entry into self-employment. The result that these "success taxes" discourage entrepreneurial entry is consistent with the risksharing framework of Domar and Musgrave (1944), since high marginal taxes amplify the asymmetry in a tax system where losses below bankruptcy level are not tax-credited.

The policy interest in taxes extends beyond the number of small businesses, and also includes the value of the firms. Previous research however has focused only on the effect of taxes on the quantity of entrepreneurship, such as the share of entrepreneurs (or selfemployed) or the probability that an individual enters entrepreneurship. However another interesting margin in terms of social and private value is the quality of the entrepreneurial firms. Clearly not all firms are equally successful or contribute equally to the general welfare of society. Crawford and Freedman (2010) review policy research on small business taxation and argue that policies which aim to increase small business activity do not automatically create innovative entrepreneurship.

We analyze the effect of taxes jointly on quality and quantity of entrepreneurship; we use a dynamic forward-looking framework where individuals decide to create firms by taking into account all future utilities and options. Our results indicate that in a dynamic setting with a high level of commitment progressive taxes can increase entry into self-employment, while 
reducing average quality of the firm. These findings are in contrast to the theoretical prediction of success taxes on entrepreneurship proposed by Gentry and Hubbard (2000), where highly progressive taxes unambiguously lead to less entrepreneurship. The mechanism we suggest by which taxes potentially increase self-employment is also novel. This happens not through risk smoothing or tax evasion, but because progressive taxes reduce the opportunity cost of pursuing a mediocre business idea rather than searching for a better one. Assuming that the start-up decision with a given idea involves an element of commitment, there is an option value associated with waiting for a better business idea. Progressive taxes reduce this option value by disproportionately taxing the most successful firms. One implication of these results is that empirical investigation of the effect of taxation on self-employment can underestimate the distortionary effects of progressive taxes. Distortions are underestimated when - as is generally the case - only the quantity but not the quality of self-employment is studied.

Our results have parallels in the theory of equilibrium unemployment (Pissarides 1990; Ljungqvist and Sargent 1995) and in the investment under uncertainty literature (Dixit and Pindyck 1994). With risk and irreversible investments the issue of timing becomes important. There is an option value of waiting for better market prospects, similar to the entrepreneur in our model that can wait for a business idea with higher potential. While entrepreneurial entry is not touched upon by Dixit and Pindyck (1994), Panteghini (2007) uses this recursive framework to analyze firm investment decisions. The effect of progressive taxes on the quantity and quality of entry in our model can be interpreted more broadly than entrepreneurial entry. It applies to any recursive decision where investment today implies 
an opportunity cost in terms of investment in the future.

\section{Quality and Quantity of Entrepreneurship}

Entrepreneurship is a multifaceted phenomenon, distinct from other economic activities with respect to aspects such as risk, its dynamic nature (Schumpeter 1934), uncertainty (Knight 1921), alertness to change (Kirzner 1967) and managerial talent (Lucas 1978). The multiple aspects that distinguish entrepreneurship in general, and the effects of taxation on entrepreneurial activity in particular, have been proved difficult to capture with any one economic model (Henrekson and Sanandaji 2011). To the extent that neoclassical economists have successfully modeled entrepreneurship they have highlighted only a few of entrepreneurial characteristic in any single model, aware that this does not constitute a complete model of entrepreneurship (Lucas 1978; Kihlstrom et al. 1979; Kanbur 1982; Aghion and Howitt 1992; Cagetti and De Nardi 2006). Our focus will be on the effect of taxes on the timing of entry and how this impacts the total amount of self-employment and the average quality of the entrepreneurial firm. The potential entrepreneur decides whether to start a firm with a given entrepreneurial innovation or business idea or to remain employed and search for a new idea. Arguably the most important role entrepreneurs assume in the economy is that of innovators which is a motivation for our focus on the quality of the business idea.

The first important decision any prospective entrepreneur has to make is whether to start a firm or to work for someone else. In our model in each period the individual discovers 
an "entrepreneurial idea"; he then decides whether to use it to start a firm or to continue searching while remaining employed. The value of these innovations or business ideas differs, which represents the quality of entrepreneurship in our model. In our model, the quality and quantity of entrepreneurship are the result of a single decision, whether to start a business employing the newly discovered idea, rather than two separate optimization margins. If the prospective entrepreneur does not act on the idea upon its receipt it is assumed to be lost. This reflects the role of the entrepreneur as reacting to business opportunity in changing markets. Once a person decides to start a firm he will earn profits that depend on the quality of the business idea. The share of workers that decide to start firms represents the quantity of entrepreneurship. Anecdotally, the decision between starting a firm with the best available idea and waiting to search for a better idea is important for some prospective entrepreneurs. Entrepreneurship magazines sometimes discuss this dilemma. One self-help entrepreneurship video asks, "Should I get started with a somewhat imperfect business or wait until I have the "perfect" business idea?" (Bickett 2011). Serial entrepreneur Howard Tullman, who writes books and articles advising entrepreneurs, has also discussed this issue arguing that many potential entrepreneurs wait too long to find the perfect idea instead of starting their firm. One of his lessons for entrepreneurs is therefore, "Don't wait until it's perfect. Start with what you have." (Tullman 2007)

Quality can be thought of as representing the social value created by the firm. This can occur through technological innovations, new or improved goods, or more efficient ways of producing existing products. Entrepreneurial ventures differ in the value generated for society. Identifying a market niche and opening a new restaurant in a neighborhood can be 
valuable entrepreneurship, but not as valuable as creating a new concept that leads to an entire chain of restaurants. From the perspective of policy makers it is not only important how many people become entrepreneurs. It also matters that these individuals pursue the best possible ideas, exert high levels of effort, bring together factors needed for successful ventures and create fast growing firms that create as many jobs and as much consumer surplus as possible. A proxy for entrepreneurial quality is the market value of the firm that they create. Policymakers who wish to encourage entrepreneurship are seeking both quantity and quality. One Google or Amazon is worth thousands of smaller entrepreneurial firms in terms of jobs, value added to gross domestic product and technological innovation.

We assume that entrepreneurs cannot search for new business ideas while managing their firms; this is the opportunity cost of pursuing one project. For simplicity we abstract from learning by doing: ideas cannot be improved upon once the project is undertaken. Entrepreneurial ideas are not correlated over time. We also abstract from any general equilibrium considerations; in particular workers' wages are not determined in equilibrium but are given. This is not unreasonable as the entrepreneurial sector in most western economies is small and thus unlikely to affect equilibrium wages through the supply of labor (although the effect on the demand of labor can be much more important). Lastly the behavior of other entrepreneurs does not affect the returns faced by potential entrants. ${ }^{1}$

People who choose not to enter entrepreneurship and search for better ideas will earn a fixed wage and receive another entrepreneurial idea in the next period. Each period a certain

\footnotetext{
${ }^{1}$ There is a theoretical justification for this assumption. Entrepreneurship is innovative in nature, and can open up new markets and opportunities for other entrepreneurs. For this reason, and in contrast to other factors of production, a higher level of preexisting entrepreneurship does not necessarily diminish the marginal return for other entrepreneurs (Henrekson 2007).
} 
fraction of entrepreneurs fails or quits and returns to the pool of workers. The wage rate is the same for all and can be interpreted as the relative advantage of employment vs. selfemployment. Crucially, the value of remaining a worker is the sum of wage income and the discounted option value of possibly discovering a better entrepreneurial idea in the future.

\subsection{The Environment}

The economy is populated by a continuum of infinitely lived agents of measure one. Each individual maximizes the discounted value of his life time utility, $\sum \beta^{t} u\left(c_{t}\right)$, where $c_{t}$ denotes consumption in period $\mathrm{t}$ and $\beta$ is the discount factor; $\beta$ is strictly greater than zero and smaller than one. We will not analyze savings decision and further assume that agents are risk neutral. The utility function has the form $u\left(c_{t}\right)=c_{t}$, so that the problem facing the agent is to maximize the discounted value of consumption at present. Because of risk neutrality the Domar and Musgrave (1944) style variation smoothing effect of taxes on marginal investment is not included in the model, and is therefore not the driving mechanism for the results.

At the beginning of each period every individual receives an exogenous entrepreneurial idea, $\theta$, drawn from a generic distribution, $F(\theta)$, defined over the positive interval $\left[\theta_{l}, \theta_{h}\right]$. Upon observing the value of $\theta$ the agent chooses between working on the market for wage $w$ while looking for a better entrepreneurial idea or using the business idea to start a firm and earn the profit generated. Entrepreneurs receive the profits made by their firm, $Y_{t}^{e}=f\left(\theta_{t}\right)$; in our simplified economy $Y_{t}^{e}=\theta_{t}$. The value of the entrepreneurial idea, $\theta_{t}$, is identically and independently distributed over time. Because there is neither capital nor saving in the model $c_{t}=w$ for workers and $c_{t}=\theta_{t}$ for entrepreneurs. 


\subsection{Equilibrium}

The problem can be written in a recursive form:

$$
V(\theta)=\max \left\{V^{e}(\theta), V^{s}(\theta)\right\}
$$

where $V^{s}(\theta)$ is the value function for the worker, and $V^{e}(\theta)$ is the value function for the entrepreneur. These value functions can be expressed as follows:

$$
\begin{gathered}
V^{s}(\theta)=w+\beta \int_{\theta} V(\theta) d F(\theta) \\
V^{e}(\theta)=\theta+\beta\left[p V^{s}(\theta)+(1-p) V^{e}(\theta)\right]
\end{gathered}
$$

In formula (1) the integral value on the right hand side (RHS) is the discounted option value of waiting one more period and drawing one more time from the distribution of entrepreneurial ideas. Since $\theta$ is independently distributed over time this value is constant. This implies that $V^{s}(\theta)$ is constant with respect to $\theta$.

The value function for the entrepreneur is the discounted value of the profit earned in the current period and of the profits earned in future periods, if the entrepreneurial activity continues. With probability $p$ in fact the entrepreneur might be forced out of business and into the salaried-workers segment of the economy. As a salaried worker however he might still be looking for a new entrepreneurial idea to create a new firm. The value function for the entrepreneur might be rearranged as follows: 


$$
V^{e}(\theta)=\frac{\theta}{1-\beta(1-p)}+\frac{\beta p}{1-\beta(1-p)} V^{s}(\theta)
$$

notice that $V^{e}(\theta)$ is strictly increasing (linear) in $\theta$.

We define $\theta^{*}$ as the "reservation entrepreneurial idea". It represents the quality level of an entrepreneurial idea such that below it the agent will find it optimal to work in the market; for every idea above this level the agent will prefer to start a firm and earn a profit. In particular $\theta^{*}$ is defined as

$$
\theta^{*}:\left\{\theta \in\left[\theta_{l}, \theta_{h}\right]: V^{s}(\theta)=V^{e}(\theta)\right\}
$$

which implies:

$$
\begin{aligned}
V^{s}\left(\theta^{*}\right) & =\frac{\theta^{*}}{1-\beta(1-p)}+\frac{\beta p}{1-\beta(1-p)} V^{s}\left(\theta^{*}\right) \\
V^{s}\left(\theta^{*}\right) & =\frac{\theta^{*}}{1-\beta}
\end{aligned}
$$

Using the reservation value, $\theta^{*}$, and (3) we can rewrite (1) as:

$$
V^{s}(\theta)=\frac{1-\beta(1-p)}{1-\beta} \frac{w+\frac{\beta}{1-\beta(1-p)} \int_{\theta^{*}}^{\theta_{h}} \theta d F(\theta)}{1+\beta p-\beta F\left(\theta^{*}\right)}
$$

$\theta^{*}$ will then be the solution to

$$
w+\gamma \int_{\theta^{*}}^{\theta_{h}} \theta d F(\theta)=\frac{\gamma}{\beta} \theta^{*}\left[1+\beta p-\beta F\left(\theta^{*}\right)\right]
$$


with $\gamma=\frac{\beta}{1-\beta(1-p)}$. In the appendix we discuss the conditions required for the existence and uniqueness of this equilibrium.

The partial equilibrium model outlined above has certain useful features that will allow us to capture important determinants of entrepreneurial entry. This is not to deny some limitations, such as not taking into account the effects of entrepreneurs' decisions on the rest of the economy. As we explained above this is a smaller problem if the entrepreneurial sector is small with respect to the rest of the economy in the mechanism investigated, such as the supply of workers (entrepreneurs probably have a more important role in determining productivity growth and the demand for labour). One could expand the model with an additional sector, such as a traditional corporate sector, and set the wage equal to the marginal product of that sector. The agent will then have to allocate labor between the two sectors and this will determine an equilibrium value for the wage. We do not think that this would add much to the intuition contained in the following sections, especially since the self-employed (of which only some are true entrepreneurs) constitute no more than around one tenth of all workers in the United States and most industrialized countries. Note that we also abstract from entry costs. The inclusion of entry costs in the model will affect $\theta^{*}$, increasing the level of profits required by an entrepreneur to start a firm. However it will not affect the comparative static analysis of an increase in tax rates presented in the rest of this article. In fact, $\theta$ can be interpreted as the company profit level net of any costs incurred by the firm - entry costs, fixed and variable costs. In the Appendix we show how the inclusion of fixed costs changes $\theta^{*}$. 


\section{Taxation and Entrepreneurial Entry}

This section investigates the effect of taxation on the decision of starting a firm. We consider

proportional and progressive taxes on business and labor income. Taxes on entrepreneurs should be interpreted as the effective tax rate of the proprietor on all income from business activity. Likewise, personal taxes should be interpreted broadly.

The first result is that proportional taxes do not affect entrepreneurial entry if the tax rates on business and labor income are equal (since other margins such as leisure are excluded). Our main result is that progressive taxes do have an effect on entrepreneurial entry even when the labor and business tax schedules are identical. In particular progressive tax schedules that decrease the workers' option value of waiting for a better idea result in a decline in the average quality of entrepreneurial firms accompanied by a reduction in the waiting time to enter entrepreneurship, which increases the number of entrepreneurs in the economy.

\subsection{Proportional Taxation}

Let's call the proportional tax rate applied to business income $\tau_{\pi}$ and the proportional tax rate applied to labor income $\tau_{w}$. The value functions (3) and (5) become

$$
\begin{gathered}
V^{s}(\theta)=\frac{1-\beta(1-p)}{1-\beta} \frac{\left(1-\tau_{w}\right) w+\left(1-\tau_{\pi}\right) \frac{\beta}{1-\beta(1-p)} \int_{\theta^{*}}^{\theta_{h}} \theta d F(\theta)}{1+\beta p-\beta F\left(\theta^{*}\right)} \\
V^{e}(\theta)=\frac{\left(1-\tau_{\pi}\right) \gamma \theta^{*}}{\beta}+\gamma p V^{s}\left(\theta^{*}\right)
\end{gathered}
$$


and $\theta_{\tau}^{*}$ is defined analogously to $\theta^{*}$ by:

$$
\left(1-\tau_{w}\right) w+\left(1-\tau_{\pi}\right) \gamma \int_{\theta_{\tau}^{*}}^{\theta_{h}} \theta d F(\theta)=\left(1-\tau_{\pi}\right) \frac{\gamma}{\beta} \theta_{\tau}^{*}\left[1+\beta p-\beta F\left(\theta_{\tau}^{*}\right)\right]
$$

From (9) we immediately derive the two following propositions.

Proposition 1 If $\tau_{w}=\tau_{\pi}=\tau$ then $\theta_{\tau}^{*}$ does not depend on $\tau$ and $\theta_{\tau}^{*}=\theta^{*}$. Hence when business and labor income are subject to proportional taxation and the tax rates are identical, the equilibrium in the economy is the same as in the case with no taxes.

Proof. The result follows immediately from (9). When $\tau_{w}=\tau_{\pi}=\tau$ equation (9) simplifies to equation (6).

Proposition 2 With proportional taxation, an increase in the tax rate on wages will lead to more entrepreneurial entry in equilibrium. An increase in the tax rate on business income will lead to less entrepreneurial entry in equilibrium.

Proof. See Appendix.

Proportional taxes decrease the income generated by either entrepreneurship or wagework. Obviously when the tax rate on business income is higher than the tax rate on wages there will be less entrepreneurial entry and fewer entrepreneurs in equilibrium than when the tax rates are the same. This follows from the definition of marginal entrepreneur: this individual is indifferent between working for a salary and being a self-employed. If suddenly taxes on business income go up, the individual who was indifferent between self-employment and employment at the previous tax rate will not be indifferent anymore. The returns from 
entrepreneurship will have to be higher to compensate for the higher tax rate. The opposite is true when the tax rate on business income is lower that the tax rate on wages. The previous proposition also suggests that an increase in the tax rate on wages will increase entrepreneurial entry in the economy, while an increase in business income tax rates will decrease entrepreneurship. Notice moreover that in this model, an increase in entrepreneurial entry is associated with a decrease in the average firm quality since the individuals who are entering entrepreneurship are the marginal ones, those whose entrepreneurial ideas are of worse quality than the existing firms. The opposite is true when entrepreneurial entry decreases. A decrease in the number of entrepreneurs in the economy is associated with an increase in the average firm quality.

\subsection{Progressive Taxation}

Let us now consider the effect of a progressive tax schedule. Consider a simple progressive structure for taxation and call $T_{w}$ the progressive schedule for labor income and $T_{\pi}$ the progressive schedule for business income. Higher levels of income will be taxed at higher rates. In particular

$$
\begin{aligned}
T_{w} & =0 & & w<\hat{w} \\
& =\tau_{w} & & w \geq \hat{w}
\end{aligned}
$$




$$
\begin{array}{rlrl}
T_{\pi} & =0 & & \theta<\hat{\theta} \\
& =\tau_{\pi} & \theta \geq \hat{\theta}
\end{array}
$$

where $\tau_{w}>0$, and $\tau_{\pi}>0$. To further simplify the problem and allow us to make some interesting comparisons, let's assume that $\tau_{w}=\tau_{\pi}=\tau$ and $\hat{\theta}=\hat{w}$. The tax schedules for labor and business income are identical. Figure 1 provides an example of the equilibrium point $\theta^{*}$ when $\theta^{*}<\hat{\theta}$. In the figure all individuals with an unobservable entrepreneurial idea, $\theta$, above the threshold, $\theta^{*}$, will choose to become entrepreneurs. The others will decide to be workers and wait for next period's entrepreneurial draw. Notice how entrepreneurial income has a kink because of the progressive nature of taxation.

The next two sections provide a more rigorous mathematical characterization of the equilibrium point and the effect of a change in the top tax rate. We distinguish between two cases: first we study the effect of progressive taxes on entrepreneurship when the income of the marginal entrepreneur - the individual who is just indifferent between starting his or her own firm and working for someone else - is below the top income bracket. Later we analyze the effect of progressive taxes when the income of the marginal entrepreneur is within the top income bracket. 
3.2.1 The Marginal Entrepreneur's Income Is Not in the Top Bracket $\left(\hat{\theta}>\theta^{*}\right)$

In this case the value functions can be written as

$$
\begin{array}{rlr}
V_{\tau}^{s}(\theta)=w+\beta V_{\tau}^{s}(\theta) F\left(\theta_{\tau}^{*}\right)+\gamma p V^{s}(\theta)+\frac{\beta}{1-\beta} \int_{\theta_{\tau}^{*}}^{\theta_{h}} \theta d F(\theta)-\tau \frac{\beta}{1-\beta} \int_{\hat{\theta}}^{\theta_{h}}(\theta-\hat{\theta}) d F(\theta) & \text { for } \theta<\hat{\theta} \\
V_{\tau}^{e}(\theta) & =\frac{\gamma \theta}{\beta}+\gamma p V^{s}(\theta) & \text { for } \theta \geq \hat{\theta} \\
& =\frac{\theta-\tau(\theta-\hat{\theta})}{1-\beta}+\gamma p V^{s}(\theta) &
\end{array}
$$

and $\theta_{\tau}^{*}$ is the solution to:

$$
w+\gamma \int_{\theta_{\tau}^{*}}^{\theta_{h}} \theta d F(\theta)-\tau \gamma \int_{\hat{\theta}}^{\theta_{h}}(\theta-\hat{\theta}) d F(\theta)=\frac{\gamma}{\beta} \theta_{\tau}^{*}\left[1+\beta p-\beta F\left(\theta_{\tau}^{*}\right)\right]
$$

In this case the effect of an increase in the tax rate is summarized by the following proposition.

Proposition 3 With a progressive tax schedule when the marginal entrepreneur's income is below the top tax bracket, an increase in the top marginal tax rate causes a decrease in the reservation entrepreneurial idea, hence an increase in entrepreneurial entry and a decrease in the average firm quality in the economy.

Proof. See Appendix.

The previous proposition states that even if business income and wages are taxed at 
the same level, the "reservation entrepreneurial idea" in this case is lower than in the case with no taxes or equal proportional tax rates for business and wage incomes. Two identical economies, one with a progressive tax schedule with equal marginal rates on business and wage incomes, and one with a proportional tax schedule with equal marginal rates on business and wage incomes, will have different levels of entrepreneurial activity. In particular the former will have more entrepreneurs but average firm quality will be lower. Moreover, as the top marginal rate increases more agents will choose to become entrepreneurs and the average quality of entrepreneurial firms will decrease.

The intuition behind this result is that convex taxes disproportionally decrease option value of working and searching for new ideas. Since the most successful businesses will be taxed at a higher rate the incentive to wait for better entrepreneurial ideas are diminished. Some workers with medium value ideas prefer to start a firm, and thus give up the chance of waiting and finding a better idea. Figure 2 illustrates this mechanism graphically: an increase in the top marginal tax rate decreases workers' option value as the best ideas will be taxed more heavily; this will prompt more individuals to join the ranks of the entrepreneurs with lower quality firms.

Waiting for an entrepreneurial idea can be viewed as a form of passive search. In that case our model predicts that an increase in the convexity of the tax schedule can decrease search activity and make people more likely to hold on to their current occupation. Gentry and Hubbard (2004) empirically demonstrate that tax progressivity decreases job turnover. 


\subsubsection{The Marginal Entrepreneur's Income is in the Top Bracket $\left(\theta^{*}>\hat{\theta}\right)$}

The effect of an increase of the top marginal rate on entrepreneurial activity is uncertain when the marginal entrepreneur is in the top bracket (i.e. the bracket at which the change occurs). The reason is that there are two effects that work in opposite directions. First, there is the decrease in the value of being a worker due to the decrease in the option value of searching for a better idea, as described in the previous section. Second, there is a decrease in the value of being a (successful) entrepreneur due to an increase in the share of income claimed by the government as taxes.

Let us ignore, for now, the effect on the option value of workers and only look at the direct effect of an increased tax rate on the marginal entrepreneur. For entrepreneurs in the top tax bracket, an increase in the marginal tax rate (from $\tau$ to $\tau^{\prime}$ ) decreases the value of being an entrepreneur vis-a-vis the value of working. Since this is true for all business ideas

above $\hat{\theta}$, it also holds for the marginal entrepreneur earning a pre-tax profit equal to $\theta_{\tau}^{*}>\hat{\theta}$. However the marginal entrepreneur was by definition indifferent between salaried work and entrepreneurship when the tax rate was $\tau$. Since the tax rate has now increased, the after-tax profit is lower and the former marginal entrepreneur is no longer indifferent between being an entrepreneur and a worker. Instead he or she strictly prefers being a worker.

In other words, since taxes have increased the pre-tax profit that an entrepreneur needs to earn in order to be indifferent between working and starting a firm also has to increase. Because of the decrease in after tax profits, the reservation entrepreneurial idea must increase following an increase in the top marginal tax rate for the agent to remain indifferent. Figure 3 illustrates this effect on $\theta^{*}$. 
Notice that the figure does not show the effect of an increase in the top tax rate on the value of being a worker described earlier and illustrated in figure 2. Since this effect goes in the opposite direction, the overall impact of an increase in the top marginal tax rate on entrepreneurial activity cannot be determined without further assumptions on the distribution of the entrepreneurial ideas and the relative positions of $\theta^{*}$ and $\hat{\theta}$. This is true irrespective of whether labor income is taxed at the top rate or not. The Appendix provides a more rigorous mathematical proof that supports the intuition provided above.

\subsubsection{Discussion}

We have shown that the effect of an increase in the top marginal tax rate depends on the position of the marginal entrepreneur. If the income of the marginal entrepreneur is not directly affected by the change in tax rates then an increase in marginal tax rates will undoubtedly lead to an increase in entrepreneurial activity and a decrease in the average quality of firms. The reason for this result is that "success taxes" will decrease the value of waiting for a better idea, so that some people will settle for lower quality ideas. If instead the income of the marginal entrepreneur is in the top bracket then the final result depends on the relative strength of the two opposite effects. On the one hand there is the decrease in the option value of being a worker; on the other hand there is the decrease in the earnings of the marginal entrepreneur which will cause only those with better entrepreneurial ideas to become entrepreneurs.

The relative strength of these effects depends in part on the "persistent" nature of the entrepreneur's business idea once the entry decision has been made. Our assumption of 
not allowing the entrepreneurs to change or improve their business idea for as long as their company lasts is equivalent to a model in which the "original" idea implemented as a business perfectly predicts future ideas: future draws are equal to the current one (the current state is an "absorbing state"). If we were to relax this assumption while keeping the other features of our approach, we would have a model in which business owners have a chance at increasing their profits in every period by receiving better ideas. They still retain the opportunity to operate the original business in case their new idea is of lower quality. Over time we would observe firms grow until they are hit by a random "death" shock. Since in our model agents have perfect foresight, this expected growth is incorporated in their current decision of whether to start a firm or not, through their option value. An increase in the progressivity of the tax schedule will affect their decision through channels analogous to those described in this article. However the magnitude of these effects would depend on the correlation of ideas over time. Intuitively, a positive correlation implies higher expected future growth and hence a bigger decrease in the option value of starting a business when the top marginal rates go up. The effect of progressivity is not as important if the correlation of ideas is zero or even negative.

\section{Empirical Implications}

Since high, progressive taxes compress the return to ideas, the minimum quality of a business idea worth pursuing decreases. Because high marginal taxes reduce the private value of top quality projects, potential entrepreneurs may settle for medium quality business projects rather than pursuing the small chance of a brilliant idea in the future. It is important to 
emphasize that the model in this paper points to merely one mechanism through which high taxes can have opposite effects on high and low quality entrepreneurship, and that other mechanisms are possible.

The welfare effect of taxes in this model is negative as taxes cause a distortion in the choice between search and entry decisions. The societal welfare implications may be even more negative than individual welfare if high quality entrepreneurial ideas are disproportionally important for technological progress. Nordhaus (2004) and Kaplan et al. (2009) estimate that entrepreneurs only capture a small fraction of the innovation surplus they create, which may be even more true for important innovations.

From an empirical standpoint, measuring the impact of taxation on entrepreneurial activity and quality of the firms in particular is a difficult task, due both to a lack of data on entrepreneurial quality and the absence of reliable policy experiments. The evidence presented here should therefore be viewed as suggestive, rather than definitive. We first discuss the evidence provided by other articles, then discuss the results we obtain by using data collected by the Global Entrepreneurship Monitor, the World Bank and Eurostat.

\subsection{Taxes and Entrepreneurship in Previous Articles}

Mooij and Nicodeme (2008) investigate the link between corporate tax rates and small business activity in Europe, showing that firms are quite sensitive in their incorporation decision with respect to the tax rate. Bruce and Deskins (2012) investigate the association between tax rates and small business activity. They find that larger shares of the workforce are sole proprietors in states with more progressive personal income tax rates, consistent with 
the model in this paper. Henrekson and Sanandaji (2013) measures high quality entrepreneurship as billionaires who become rich through founding their own firms. Lower quality entrepreneurship is measured as non-agricultural self-employment. They find that high and low quality entrepreneurship are negatively correlated. Countries with higher rates of selfemployment tend to have lower per capita numbers of billionaire entrepreneurs. High taxes on firms are found to be negatively correlated with high-quality entrepreneurship and positively related to self-employment. The latter result is similarly in line with the idea proposed in this article that higher marginal taxes might increase the number of entrepreneurs but decrease their quality.

Another empirical study finds results which correspond strongly with the theoretical predictions in this paper. Kneller and McGowan (2011) study the effect of a change in marginal corporate taxes in advanced economies. They suggest that the effect of an increase in taxes depends on the income bracket at which the tax change occurs. Increases in marginal tax rates applied at low income levels affect entry negatively, while the opposite is true when the change happens at higher income levels. These empirical findings are consistent with both Domar and Musgrave (1944) risk sharing model and our model. Tax increases on top earners likely apply to income brackets well above the one where the marginal entrepreneur is located. In this case proposition (3) suggests that the effect of tax increases on the entrepreneurial entry rate should be positive. This counter-intuitive result (from the point of view of the standard model) is precisely what Kneller and McGowan find. When the change in the marginal rate is at lower levels it is more likely that it is directly affecting the earnings of the marginal entrepreneurs. In this case, as shown in the Appendix, the effect is 
indeterminate and depends on the distribution of entrepreneurial talent, the relative distance between the income of the marginal entrepreneur and the income level at which the change is taking effect. Kneller and McGowan find that the effect on entrepreneurial entry of an increase in marginal tax rates at lower income levels is negative. It seems that the direct effect on the income of the entrepreneurs is stronger than the indirect effect on their search option. Kneller and McGowan (2011) do not investigate the quality of entrepreneurial firms.

\subsection{Additional Evidence on the Effect of Taxes on Entrepreneur- ship}

We now discuss some additional empirical evidence. Data from the Global Entrepreneurship Monitor (GEM) allows for cross-country estimates of high-quality and low-quality entrepreneurship. While the World Bank "Doing Business" project has calculated the tax rate faced by a standardized small firm in a large number of countries.

\subsubsection{Taxes and Entrepreneurial Activity in the Global Entrepreneurship Mon- itor}

For the first empirical exercise we rely on data on high and low-quality entrepreneurship as measured by the GEM. GEM provides one of the most widely used measures of entrepreneurship and self-employment (e.g. Bygrave et al. 2001, Acs and Szerb 2009, Ardagna and Lusardi 2010, Lerner 2009, Autio and Levie 2008). GEM collects a measure of established high quality entrepreneurs called "High-Growth Established Entrepreneurs" (Autio 2007). This refers to the number of established owner-managed firms with at least 20 employees. 
Analogously, we refer to the number of established owner-managed firms with less than 20 employees as "Low-Growth Established Entrepreneurs". We rely on Xavier et al. (2013) for this measure. Two sources from two different years are used since GEM does not report both numbers in any single report. The numbers reported regarding "High-Growth Established Entrepreneurs" are for the years 2000-2006 while Low-Growth Established Entrepreneurs refers to 2012, the latest available year. Our sample consists of 38 countries for which the GEM data was available for both Low-Growth and High-Growth Established Entrepreneurs. ${ }^{2}$

Besides measuring the quality of firms we also need to summarize the numerous tax rates faced by entrepreneurs. Generally, entrepreneurs pay many different taxes, with the tax rate depending on the earnings of the firm and the organizational form. The tax treatment of sole proprietorships and limited liability companies, for example, are often different. In an ambitious project The World Bank created a standardized small firm (with 5 owners, limited liability, gross margin of $20 \%$ etc.) and with the help of PricewaterhouseCoopers calculated the "Total Tax Rate" faced by the firm in a number of countries. This included profit or corporate income tax, individual level taxes, social contributions capital gains taxes. We use the World Bank's standardized "Total Tax Rate" as a proxy for the marginal tax rate facing entrepreneurs. The World Bank's "Ease of doing business index" is used to proxy for the regulatory burden facing new firms. This metric is calculated by a panel of experts in the World Bank and attempts to measure how difficult it is to set up a new firm in various countries. Higher numbers signify a more burdensome regulatory environment. Per capita GDP numbers from the World Bank are also used.

\footnotetext{
${ }^{2}$ The results are qualitatively similar if we run the regressions with the entire sample available for each entrepreneurship measure.
} 
Table 1 and Table 2 show the correlation between tax rates and high-quality (20 employees or more) and low-quality (less than 20 employees) established entrepreneurial firms. Taxes consistently correlate negatively with high-quality entrepreneurship. This holds also when controlling for per capita GDP and the estimated level of regulatory burden. Taxes however correlate positively with low-quality entrepreneurship. This correlation is only statistically significant when not controlling for per capita GDP and the level of regulatory burden, though the sign is positive in those specifications. The small size of the sample should be taken into account when interpreting significance levels.

\subsection{Discussion of the Evidence}

We should again emphasize that these correlations are at best suggestive. Even if the relationship between taxes and entrepreneurial quality is interpreted as causal, the mechanism which causes it may be different than the one outlined in our model. There are other possible reasons why countries with high marginal taxes would have more entrepreneurs but of lower quality, such as tax evasion. Another possible explanation is that high taxes shift the distribution of entrepreneurs from those motivated in pecuniary rewards to those with non-pecuniary motivation. Non-pecuniary benefits of self-employment have recently been emphasized by Hurst and Pugsley (2011). These include being one's own boss, "hobbyentrepreneurship" and greater flexibility in hours, which is especially important for women. Since non-pecuniary benefits are not subject to taxes, higher taxes could therefore cause a higher share of the self-employed in a country to consist of entrepreneurs who are less interested in growth and profits, rather than in fewer entrepreneurs. 
When relying on cross-country evidence the risk is always present that the relationships are not causal, and instead the results of omitted variables, such as regulations or the rate of other taxes. While the data does not allow us to establish a clear causal relationship, the empirical patterns observed across countries are consistent with the theory proposed, as high marginal tax rates are associated with more entrepreneurs, but of lower average

quality. While far from causal the correlations reported suggest that empirical evaluations of the relationship between taxes and entrepreneurship need to take the quality margin into account. More generally the cross-country correlations confirm that tax rates may correlate in different ways with high and low-quality entrepreneurship.

\section{Conclusions}

We study the effect of taxes on entrepreneurial entry in a dynamic setting that takes into account both the number of entrepreneurs and the quality of their firms. A novel finding is that when entry is associated with an opportunity cost in terms of searching for better ideas, progressive taxes can decrease the average quality of startups while increasing their number. Progressive taxes compress the returns to entrepreneurial activity, thus lowering the reward to high quality ideas relative to mediocre ones. While the paper focuses on entrepreneurship, the model can be interpreted as the impact of taxes on any investment choice which involves taking irreversible decisions at the cost of pursuing better options.

In various specifications higher taxes are found to reduce high quality entrepreneurship, but may at the same time increase the number of lower quality entrants. Empirical studies 
typically do not take into account the quality of entrepreneurship, and mainly focus on quantity measures, such as the probability of entry. Since we show that quality and quantity can go in opposite directions as a result of higher marginal taxes, this standard empirical framework risks leading to misguided policy conclusions. The result that high marginal taxes leave entrepreneurial entry unchanged or even encourages it should not be interpreted as a sign of small distortions if quality is not taken into account. This is especially true if the value of entrepreneurship from a social welfare perspective mainly comes from high quality ventures and innovations.

Taxes can lead to a larger share of self-employed but less entrepreneurial quality through other mechanisms as well. For example, the self-employed have an easier time evading taxes, so taxes can directly discourage the pursuit of entrepreneurial ideas, while encouraging selfemployment motivated by tax evasion only. Clearly the later type of entrepreneur is hardly the same economic entity as a new firm based on innovative ideas. Studies that point to these opposing effects of taxes and argue that taxes have ambiguous impact on entrepreneurship miss an important point. Self-employment and entrepreneurship are not ends in themselves; they are sought after by policy makers because they are thought to increase economic growth and help create high paying jobs. Even if higher taxes lead to the swelling of the ranks of the self-employed encouraging the creation of many small stagnant firms, they are still detrimental to the economy because they stifle productive and fast growing entrepreneurial ventures.

Taxes can impact quality differently than quantity in more subtle ways. Monetary income is not the only reward from entrepreneurship; many individuals have preferences conducive 
to entrepreneurship, such as a wish for independence. In a low tax environment these individuals are strongly rewarded if they create successful firms and if they choose to grow. In countries with high taxes many of these individuals may nevertheless pursue the entrepreneurial lifestyle but because of dulled economic incentives choose "comfort" in their business rather than risk, competition and expansion. The latter countries might have the same quantity of entrepreneurs as the former but end up with lower quality entrepreneurship and disparate economic outcomes. 


\section{References}

[1] Aghion P, Howitt P (1992) A model of growth through creative destruction. Econometrica $60(2): 323-351$

[2] Acs Z, Szerb L (2009) The Global Entrepreneurship Index (GEINDEX). Foundations and Trends in Entrepreneurship 5(5):341-435

[3] Ardagna S, Lusardi A (2010) Explaining International Differences in Entrepreneurship: The Role of Individual Characteristics and Regulatory Constraints. In: Lerner J and Schoar A (eds) International Differences in Entrepreneurship

[4] Autio E (2007) Global Report on High-Growth Entrepreneurship. Global Entrepreneurship Monitor

[5] Autio E, Levie J (2008) Does Entrepreneurship matter? Types of entrepreneurship and economic growth. Frontiers of Entrepreneurship Research: 28(16) Article 1.

[6] Bickett, I (2011), "A Better Way of Business", video podcast, November 222011.

[7] Bygrave W, Hay M, Lopez-Garcia P, Reynolds P (2001) The Global Entrepreneurship Monitor (GEM) model for economic growth: A study of venture capital in 19 nations. In: W. D. Bygrave WD et al. (eds.) Frontiers of Entrepreneurship Research 2001, Babson College, Wellesley, MA

[8] Bruce D (2000) Effects of the United States Tax System on Transitions Into SelfEmployment. Labour Econ 7(5): 545-74. 
[9] Bruce D, Gurley T (2004) Taxes and Entrepreneurial Entry: An Empirical Investigation Using Longitudinal Tax Return Data. Proceedings of the 97th Annual Conference on Taxation, National Tax Association, 336-343

[10] Bruce D, Schuetze H (2004) Tax Policy and Entrepreneurship. Swedish Economic Policy Review 11(2):235-65

[11] Bruce D, Deskins J (2012) Can State Tax Policies Be Used to Promote Entrepreneurial Activity? Small Bus Econ 38(4):375-97

[12] Cagetti M, De Nardi M (2006) Entrepreneurship, Frictions, and Wealth. J Polit Econ 114(5):835-70

[13] Carroll R, Holtz-Eakin D, Rider M, Rosen HS (2001) Personal Income Taxes and the Growth of Small Firms. In James Poterba (ed.), Tax Policy and the Economy, Vol. 15. Mit Press, Cambridge, MA

[14] Carroll R, Holtz-Eakin D, Rider M, Rosen HS (2000a) Entrepreneurs, Income Taxes, and Investment. In Joel B. Slemrod (ed.), Does Atlas Shrug? The Economic Consequences of Taxing the Rich. Russell Sage Foundation, New York

[15] Carroll R, Holtz-Eakin D, Rider M, Rosen HS (2000b) Income Taxes and Entrepreneurs' Use of Labor. Journal of Labor Economics 18(2):324-51

[16] Crawford C, Freedman J (2010) Small Business Taxation, in Dimensions of Tax Design: the Mirrlees Review. In: Mirrlees J, Adam S, Besley T, Blundell R, Bond S, Chote R, Gammie M, Johnson P, Myles G, Poterba J (eds). Oxford, Oxford University Press 
[17] Cullen J, Gordon R (2007) Taxes and Entrepreneurial Risk-taking: Theory and Evidence for the US. Journal of Public Economics 91(7):1479-1505

[18] Dixit A, Pindyck R (1994) Investment under Uncertainty. Princeton University Press, New Jersey

[19] Domar ED, Musgrave RA (1944) Proportional income taxation and risk-taking. Q J Econ 58(3):388-422

[20] Gentry WM, Hubbard RG (2004) The effects of progressive income taxation on job turnover. Journal of Public Economics 88(11):2301-22

[21] Gentry WM, Hubbard RG (2000) Tax Policy and Entrepreneurial Entry. Am Econ Rev $90(2): 283-87$

[22] Gordon RH (1998) Can High Personal Tax Rates Encourage Entrepreneurial Activity? IMF Staff Papers, International Monetary Fund 45(1):49-80

[23] Gordon RH, MacKie-Mason J (1994) Tax Distortions to the Choice of Organizational Form. Journal of Public Economics 55(2):279-306

[24] Henrekson M, Sanandaji T (2011) Entrepreneurship and the Theory of Taxation. Small Bus Econ 37(2):167-185

[25] Henrekson M. Sanandaji T (2013) Billionaire Entrepreneurs: A Systematic Analysis. IFN Working Paper 959

[26] Hurst E, Pugsley BW (2011) Understanding Small Business Heterogeneity. NBER Working Papers 17041 
[27] Kanniainen V, Panteghini P (2013) Tax Neutrality: Illusion or Reality? The Case of Entrepreneurship. FinanzArchiv: Public Finance Analysis 69(2): 167-193.

[28] Kanbur SM (1982) Entrepreneurial Risk Taking, Inequality, and Public Policy: An Application of Inequality Decomposition Analysis to the General Equilibrium Effects of Progressive Taxation. J Polit Econ 90(1):1-29

[29] Kaplan SN, Sensoy BA, Stromberg P (2009) Should Investors Bet on the Jockey or the Horse? Evidence from the Evolution of Firms from Early Business Plans to Public Companies. J Financ 64(1):75-115

[30] Kihlstrom RE, Laffont JJ (1979) A General Equilibrium Entrepreneurial Theory of Firm Formation Based on Risk Aversion. J Polit Econ 87(3):719-48

[31] Kirzner IM (1973) Competition and Entrepreneurship. University of Chicago Press, Chicago

[32] Kneller R, McGowan D (2011) Tax Policy and Firm Entry and Exit Dynamics: Evidence from OECD Countries. University of Nottingham working paper

[33] Knight FH (1921) Risk, uncertainty and profit. Houghton Mifflin Company, Boston

[34] Lerner J (2009) The Boulevard of Broken Dreams: Why Public Efforts to Boost Entrepreneurship and Venture Capital Have Failed - and What to Do About It. Princeton University Press, Princeton

[35] Ljungqvist L, Sargent TJ (1995) Welfare States and Unemployment. Econ Theor 6(1):143-60 
[36] Lucas RE (1978) On the Size Distribution of Business Firms. Bell J Econ 9(2):508-23.

[37] Mooij R, Nicodème G (2008) Corporate tax policy and incorporation in the EU. Int Tax Public Finan 15(4):478-498

[38] Nordhaus WD (2004) Schumpeterian Profits in the American Economy: Theory and Measurement. Cowles Foundation Discussion Papers 1457, Yale University

[39] Panteghini P (2007) Corporate Taxation in a Dynamic World. Springer, Berling

[40] Pissarides CA (1990) Equilibrium Unemployment Theory. Blackwell, Oxford

[41] Schumpeter JA (1934) The Theory of Economic Development. Harvard University Press, Cambridge

[42] Stenkula, M (2012) Taxation and entrepreneurship in a welfare state. Small Business Economics 39(1): 77-97

[43] Tullman, H (2007) Crain's Chicago Business, "Talking Management" series, February 2007

[44] Xavier R, Kelley D, Kew J, Herrington M, Vorderwülbecke A (2013), Global Entrepreneurship Monitor 2012 Global Report. Global Entrepreneurship Monitor 


\section{APPENDIX}

\section{A Existence and Uniqueness of Equilibrium}

Given that both the RHS and the LHS of equation (6) are continuous functions of $\theta^{*}$, sufficient conditions for existence of an equilibrium are:

$$
\begin{aligned}
& w>\frac{\theta_{l}(1+\beta p)-\beta E(\theta)}{1-\beta(1-p)} \\
& w<\theta^{h}
\end{aligned}
$$

These conditions describe a relationship between the market wage and the distribution of the quality of entrepreneurial projects. The second condition simply says that the best possible entrepreneurial idea must yield a return higher than the market wage. The first condition says that the wage rate should not be inferior to a quantity that depends on the distribution of entrepreneurial projects. It is positively related to the lowest entrepreneurial project and negatively related to the average entrepreneurial project. Intuitively if the lowest entrepreneurial project increases, then market wage should generally be higher. However if the lowest bound on the distribution increases the average value of entrepreneurial ideas also increases, counteracting the first effect. Generally the effect depends on the particular form of the distribution. To get a sense of how strict this requirement is consider the following. Since the thetas are defined over a positive interval we can normalize without loss of generality 
$\theta_{l}=0$. In this case the first condition simply says that the wage has to be greater than some negative number. Since the wage is non-negative by definition this is not a strict requirement.

Nothing in the structure of the problem ensures a unique solution to equation (6). Since the LHS of the equation is decreasing in $\theta^{*}$, a sufficient condition for uniqueness is:

$$
F\left(\theta^{*}\right)\left[1+\frac{\theta^{*} f\left(\theta^{*}\right)}{F\left(\theta^{*}\right)}\right] \leq \frac{1+\beta p}{\beta}
$$

This condition clearly imposes some restrictions on the shape of the distribution function of thetas that depend on the value of the parameters $\beta$ and $p$.

In our problem multiplicity of equilibria arises from the fact that agents can follow several internally consistent decision rules. Having a decision rule over decision rules will eliminate the multiplicity problem. One such decision rule is the following:

$$
\theta^{*}=\max \left\{\theta \in\left[\theta_{l}, \theta_{h}\right]: V^{s}(\theta)=V^{e}(\theta)\right\}
$$

This decision rule generates the highest utility (discounted profit). Suppose there is more than one solution to equation (6), so that different decision rules are available to the agent. Call these solutions $\theta_{1}^{*}, \theta_{2}^{*} \ldots \theta_{n}^{*}$ and let's assume, without loss of generality, that $\theta_{1}^{*}<\theta_{2}^{*}<$ $\ldots<\theta_{n}^{*}$.

Notice that $V^{e}\left(\theta^{*}\right)$ is an increasing function of $\theta^{*}$; it follows that $V^{e}\left(\theta_{1}^{*}\right)<V^{e}\left(\theta_{2}^{*}\right)<\ldots<$ $V^{e}\left(\theta_{n}^{*}\right)$. Moreover since $\theta_{i}^{*}$ for $i=1, \ldots, n$ are defined as those points that equate the value of searching and the value of entrepreneurship, it has to be the case that $V^{S}\left(\theta_{1}^{*}\right)<V^{S}\left(\theta_{2}^{*}\right)<$ $\ldots<V^{S}\left(\theta_{n}^{*}\right)$. 
Let's define $V^{e}\left(\theta \mid \theta_{i}^{*}\right)$ and $V^{s}\left(\theta \mid \theta_{i}^{*}\right)$ as the value functions for the entrepreneur and the worker when the agent chooses the $\theta_{i}^{*}$ as his decision rule. Then $V_{i}\left(\theta_{i}^{*}\right)=\max \left\{V^{e}\left(\theta \mid \theta_{i}^{*}\right), V^{s}\left(\theta \mid \theta_{i}^{*}\right)\right\}$ is the value function for the agent when using decision rule $\theta_{i}^{*}$.

Equation (4) implies that if $\theta_{i}^{*}>\theta_{j}^{*}$ then $V^{s}\left(\theta \mid \theta_{i}^{*}\right)>V^{s}\left(\theta \mid \theta_{j}^{*}\right)$; hence from equation (3) we see that $V^{e}\left(\theta \mid \theta_{i}^{*}\right)>V^{e}\left(\theta \mid \theta_{j}^{*}\right)$ for every $\theta$. It follows that for every $\theta, V_{i}\left(\theta_{i}^{*}\right) \geq V_{j}\left(\theta_{j}^{*}\right)$ when $\theta_{i}^{*}>\theta_{j}^{*}$. We conclude that the agent will choose the decision rule that will give him at least as much utility as the others. Notice however that different $\theta^{*}$ imply that the agent will choose to become an entrepreneur with different probabilities each period. In particular, the higher is $\theta^{*}$ the longer the wait to become an entrepreneur (and enjoy the higher income guaranteed by it). It is possible that an impatient agent will choose a lower $\theta^{*}$ in order to enjoy the income guaranteed by entrepreneurship sooner. We do not address this issue. 


\section{B Entry Costs}

With entry costs we can re-write (2) as:

$$
V^{e}(\theta)=\theta-E+\beta\left[p V^{s}(\theta)+(1-p) V^{e}(\theta)\right]
$$

where $E$ represents the entry costs. Following the same logic used before we obtain that $\theta^{*}$ is the solution to the following equation:

$$
w+\gamma \int_{\theta^{*}}^{\theta_{h}}(\theta-E) d F(\theta)=\frac{\gamma}{\beta}\left(\theta^{*}-E\right)\left[1+\beta p-\beta F\left(\theta^{*}\right)\right]
$$

with $\gamma=\frac{\beta}{1-\beta(1-p)}$. Note that the derivative of $\theta^{*}$ with respect to $E$ is:

$$
\frac{d \theta^{*}}{d E}=1-\frac{\beta\left(1-F\left(\theta^{*}\right)\right)}{1+\beta p-\beta F\left(\theta^{*}\right)}
$$

and with simple algebra one can prove that $\frac{d \theta^{*}}{d E}>0$, for all $\theta^{*}$.

The inclusion of entry costs in the model increases the "reservation entrepreneurial idea." The inclusion of entry costs in the model affects the rest of the formulas in this article in a similar fashion, changing the level at which in any of the previous cases it is optimal to start a firm. However the qualitative conclusion of the paper does not change: the effect of an increase in the top tax rate on the quality or quantity of entrepreneurship depends on the shape of the tax schedule, i.e. the relative position of $w, \theta^{*}$ and $\hat{\theta}$. 


\section{Proofs of Propositions}

\section{C.1 Proof of Proposition 2}

Proof. We can write (9) using the known result:

$$
E(x)=\int_{a}^{b} x d F(x)=\int_{a}^{b}(1-F(x)) d x-[(1-F(b)) b-(1-F(a)) a]
$$

which in our case implies:

$$
\int_{\theta_{\tau}^{*}}^{\theta_{h}} \theta d F(\theta)=\theta_{h}-\int_{\theta_{\tau}^{*}}^{\theta_{h}} F(\theta) d \theta-F\left(\theta_{\tau}^{*}\right) \theta_{\tau}^{*}
$$

Using this result, writing $\theta_{\tau}^{*}=\theta_{\tau}^{*}\left(\tau_{w}\right)$ and differentiating $(9)$ with respect to $\tau_{w}$ we get

$$
\frac{d \theta_{\tau}^{*}}{d \tau_{w}}=\frac{-w(1-\beta(1-p))}{\left(1-\tau_{\pi}\right)\left(1+\beta p-\beta F\left(\theta_{\tau}^{*}\right)\right)}<0
$$

Analogously we can show that:

$$
\begin{aligned}
\frac{d \theta_{\tau}^{*}}{d \tau_{\pi}} & =\frac{-\beta \int_{\theta_{\tau}^{*}}^{\theta_{h}} \theta d F(\theta)+\theta_{\tau}^{*}\left[1+\beta p-\beta F\left(\theta_{\tau}^{*}\right)\right]}{\left(1-\tau_{\pi}\right)\left[1+\beta p-\beta F\left(\theta_{\tau}^{*}\right)\right]}= \\
& =\frac{[1-\beta(1-p)]\left(1-\tau_{w}\right) w}{\left(1-\tau_{\pi}\right)^{2}\left[1+\beta p-\beta F\left(\theta_{\tau}^{*}\right)\right]}>0
\end{aligned}
$$




\section{C.2 Proof of Proposition 3}

Proof. As before, using the following expressions for the expected values

$$
\begin{aligned}
& \int_{\theta_{\tau}^{*}}^{\theta_{h}} \theta d F(\theta)=\theta_{h}-\int_{\theta_{\tau}^{*}}^{\theta_{h}} F(\theta) d \theta-F\left(\theta_{\tau}^{*}\right) \theta_{\tau}^{*} \\
& \int_{\hat{\theta}}^{\theta_{h}} \theta d F(\theta)=\theta_{h}-\int_{\hat{\theta}}^{\theta_{h}} F(\theta) d \theta-F(\hat{\theta}) \hat{\theta}
\end{aligned}
$$

writing $\theta_{\tau}^{*}=\theta_{\tau}^{*}(\tau)$ and differentiating (14) with respect to $\tau$ we get:

$$
\frac{d \theta_{\tau}^{*}}{d \tau}=\frac{\beta[1-F(\hat{\theta})]}{\left[1+\beta p-\beta F\left(\theta_{\tau}^{*}\right)\right]}[\hat{\theta}-E(\theta \mid \theta>\hat{\theta})] \leq 0
$$

\section{C.3 Analysis when the Marginal Entrepreneur's Income is in the top bracket}

C.3.1 Case 1: $\theta^{*}>\hat{\theta}>w$

In this case the equilibrium is defined by:

$$
w+\gamma \int_{\theta_{\tau}^{*}}^{\theta_{h}} \theta d F(\theta)-\tau \gamma \int_{\theta_{\tau}^{*}}^{\theta_{h}}(\theta-\hat{\theta}) d F(\theta)=\frac{\theta_{\tau}^{*}-\tau\left(\theta_{\tau}^{*}-\hat{\theta}\right)}{1-\beta(1-p)}\left[1+\beta p-\beta F\left(\theta_{\tau}^{*}\right)\right]
$$

The effect of a top marginal tax rate increase in this case is summarized by the following proposition. 
Proposition 4 With a progressive tax schedule when the marginal entrepreneur earns more than the top marginal tax rate bracket and more than the average worker, the effect of an increase in the top marginal tax rate on entrepreneurial activity is uncertain.

Proof. As before we can calculate the total derivative of (16) with respect to the tax rate

$$
\begin{aligned}
\frac{d \theta_{\tau}^{*}}{d \tau}= & \frac{\beta\left[1-F\left(\theta_{\tau}^{*}\right)\right]}{\left[1+\beta p-\beta F\left(\theta_{\tau}^{*}\right)\right](1-\tau)} . \\
& \cdot\left[\hat{\theta}-E\left(\theta \mid \theta>\theta_{\tau}^{*}\right)+\frac{\left[1+\beta p-\beta F\left(\theta_{\tau}^{*}\right)\right]}{\beta\left[1-F\left(\theta_{\tau}^{*}\right)\right]}\left(\hat{\theta}-\theta_{\tau}^{*}\right)\right]
\end{aligned}
$$

the sign of this derivative is not certain and depends on the relative position of $\hat{\theta}$ and $\theta_{\tau}^{*}$. We cannot determine the relative positions of $\theta_{\tau}^{*}$ and $\theta^{*}$ either.

\section{C.3.2 Case 2: $\theta^{*}>w>\hat{\theta}$}

We consider the case in which labor income is taxed. As in the previous section we consider the case in which the kink in the entrepreneurial value function is below the value of searching. The situation when it is above the equilibrium is exactly as in Case 1.

The value function for the entrepreneurs is still the one described in (13) while the value function for the worker becomes

$$
V_{\tau}^{s}(\theta)=w-\tau(w-\hat{w})+\beta V_{\tau}^{s}(\theta) F\left(\theta_{\tau}^{*}\right)+\gamma p V^{s}(\theta)+\gamma \int_{\theta_{\tau}^{*}}^{\theta_{h}} \theta d F(\theta)-\tau \gamma \int_{\theta_{\tau}^{*}}^{\theta_{h}}(\theta-\hat{\theta}) d F(\theta)
$$

$\theta_{\tau}^{*}$ is the solution to 


$$
w-\tau(w-\hat{w})+\gamma \int_{\theta_{\tau}^{*}}^{\theta_{h}} \theta d F(\theta)-\tau \gamma \int_{\theta_{\tau}^{*}}^{\theta_{h}}(\theta-\hat{\theta}) d F(\theta)=\frac{\theta_{\tau}^{*}-\tau\left(\theta_{\tau}^{*}-\hat{\theta}\right)}{1-\beta(1-p)}\left[1+\beta p-\beta F\left(\theta_{\tau}^{*}\right)\right]
$$

Again the effect of an increase in the top marginal tax rate is summarized by the following proposition.

Proposition 5 With a progressive tax schedule when the marginal entrepreneur earns more than the top marginal tax rate bracket but less than the average worker, the effect of an increase in the top marginal tax rate on entrepreneurial activity is uncertain.

Proof. Once again we can calculate the derivative of $\theta_{\tau}^{*}$ with respect to $\tau$ from $(18)$ :

$$
\begin{aligned}
\frac{d \theta_{\tau}^{*}}{d \tau}= & \frac{\beta\left[1-F\left(\theta_{\tau}^{*}\right)\right]}{\left[1+\beta p-\beta F\left(\theta_{\tau}^{*}\right)\right](1-\tau)} \cdot \\
& \cdot\left[\hat{\theta}-E\left(\theta \mid \theta>\theta_{\tau}^{*}\right)+\frac{\left[1-\beta F\left(\theta_{\tau}^{*}\right)\right]}{\beta\left[1-F\left(\theta_{\tau}^{*}\right)\right]}\left(\hat{\theta}-\theta_{\tau}^{*}\right)-\frac{(w-\hat{w})}{\gamma\left[1-F\left(\theta_{\tau}^{*}\right)\right]}\right]
\end{aligned}
$$

the sign of this derivative is not certain. 


\section{Tables}

Table 1. High-Growth Established Entrepreneurship and Taxes.

\begin{tabular}{lccc} 
& $(1)$ & $(2)$ & $(3)$ \\
\hline \hline Total Tax Rate & $-0.863^{* *}$ & $-0.731^{*}$ & $-1.123^{* *}$ \\
& $(0.401)$ & $(0.441)$ & $(0.448)$ \\
& & & \\
Per Capita GDP & & 0.004 & $0.014^{* *}$ \\
& & $(0.005)$ & $(0.006)$ \\
Regulation & & & \\
& & & $0.005^{* *}$ \\
Constant & & & $(0.002)$ \\
& $0.834^{* * *}$ & 0.682 & 0.354 \\
Pseudo $R^{2}$ & $(0.180)$ & $(0.273)$ & $(0.293)$ \\
\# Obs & 0.114 & 0.128 & 0.248 \\
\hline \hline
\end{tabular}

Results of a Ordinary Least Square regression. The dependent variable represents the share of the workforce who are business owner-managers with at least 20 employees, based on Global Entrepreneurship Monitor estimates. "Total Tax Rate" is the World Banks estimate of total taxes paid by a standardized small firm in different countries. Regulation refers to the World Bank estimate of regulatory burden on startups, with higher numbers signifying a lower rank and thus a heavier regulatory burden. "Per Capita GDP" represents PPP-adjusted GDP in 2009, based on World Bank data. Three stars $(* * *)$ denote statistical significance at the $1 \%$ level and two stars $(* *)$ the $5 \%$ level. 
Table 2. Low-Growth Established Entrepreneurship and Taxes.

\begin{tabular}{lccc} 
& $(1)$ & $(2)$ & $(3)$ \\
\hline \hline & & & \\
Total Tax Rate & $9.221^{* *}$ & 6.213 & 3.097 \\
& $(4.269)$ & $(4.563)$ & $(4.789)$ \\
Per Capita GDP & & -0.080 & 0.005 \\
& & $(0.049)$ & $(0.068)$ \\
Regulation & & & $0.040^{*}$ \\
& & & $(0.023)$ \\
Constant & 2.667 & $6.132^{* *}$ & 3.525 \\
& $(1.915)$ & $(2.827)$ & $(3.134)$ \\
Pseudo $R^{2}$ & 0.115 & 0.177 & 0.244 \\
\# Obs & 38 & 38 & 38 \\
\hline \hline
\end{tabular}

Results of a Ordinary Least Square regression. The dependent variable represents the share of the workforce who are business owner-managers with less than 20 employees, based on Global Entrepreneurship Monitor estimates. "Total Tax Rate" is the World Banks estimate of total taxes paid by a standardized small firm in different countries. Regulation refers to the World Bank estimate of regulatory burden on startups, with higher numbers signifying a lower rank and thus a heavier regulatory burden. "Per Capita GDP" represents PPP-adjusted GDP in 2009, based on World Bank data. Three stars $(* * *)$ denote statistical significance at the $1 \%$ level and two stars (**) the $5 \%$ level. 


\section{E Figures}

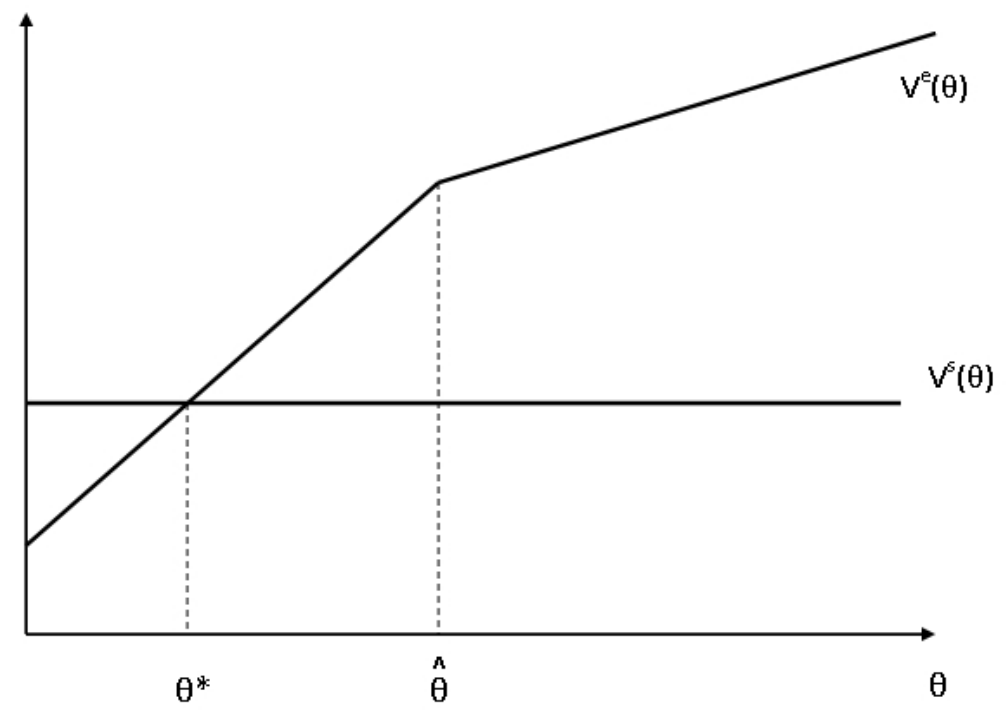

Figure 1: Graphical representation of a decision rule, $\theta^{*}$. 


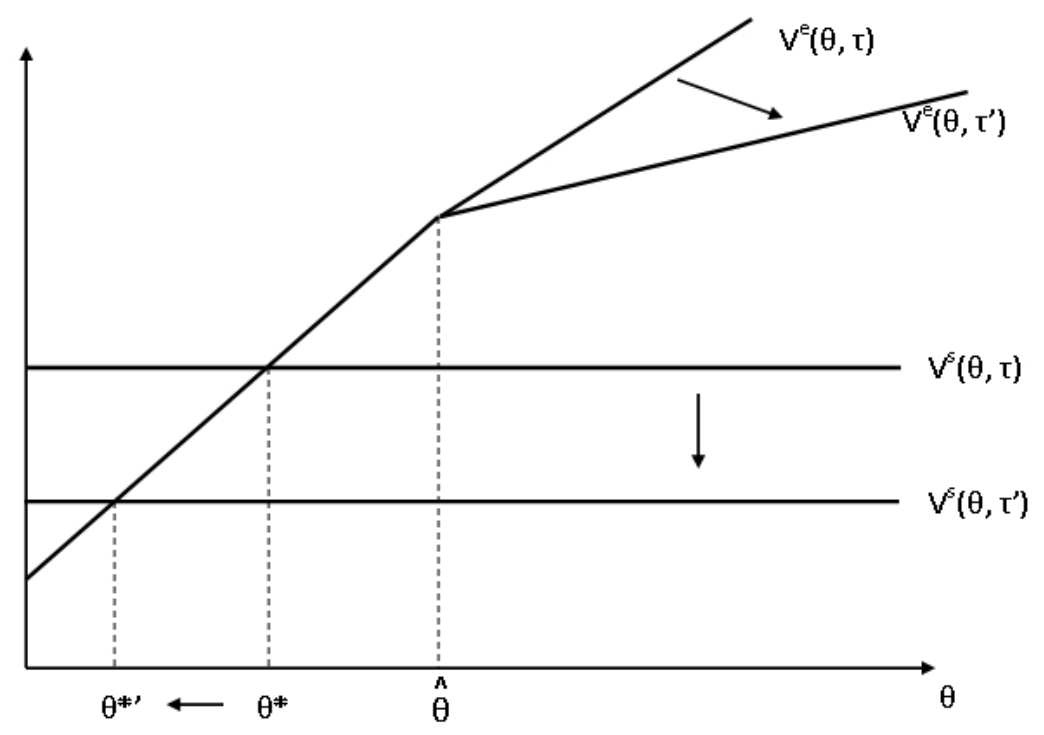

Figure 2: Indirect effect of an increase in the top rates on the quantity and quality of entrepreneurial firms. 


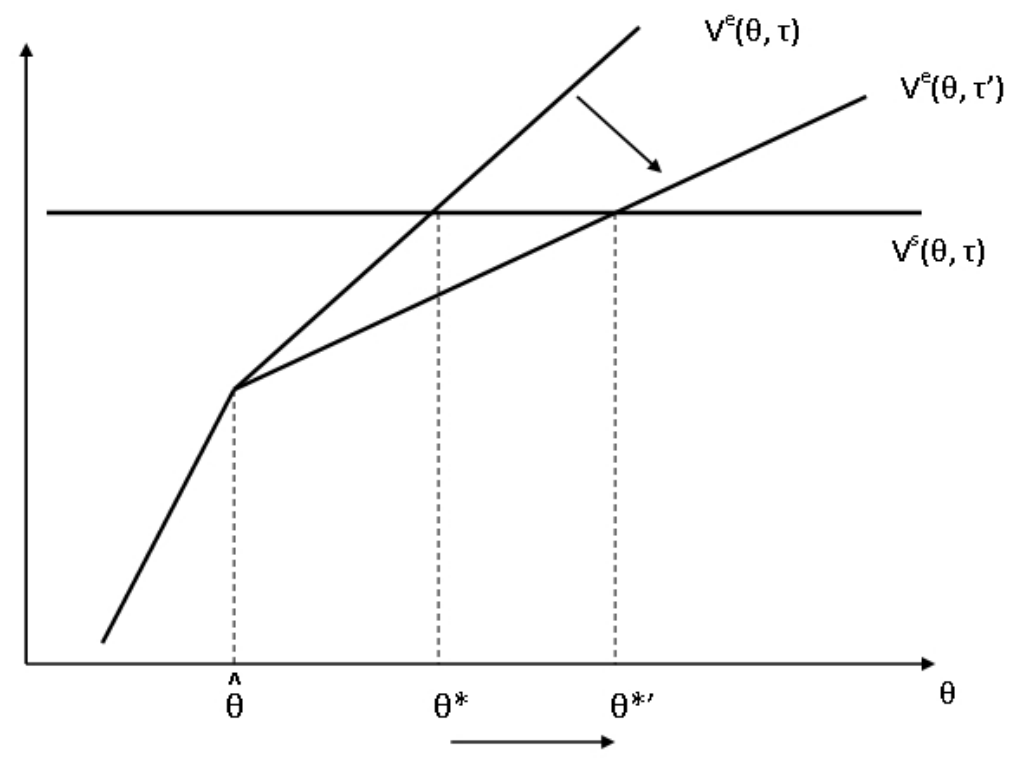

Figure 3: Direct effect of an increase in the top rates on the quantity and quality of entrepreneurial firms. 